\title{
Nurturing Sustainability in a Growing Community Pediatric Hospital Medicine Workforce
}

\author{
Rachel L Marek, MD ${ }^{1 *}$, Andrew A White, MD²
}

${ }^{1}$ Baylor College of Medicine, Houston, Texas; ${ }^{2}$ Department of Medicine, University of Washington School of Medicine, Seattle, Washington.

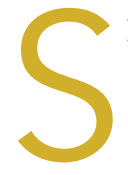

ystematic efforts to measure and compare work hours emerged in the $19^{\text {th }}$ century as laborers shifted from artisanal shops to factories, sparking debate over the appropriate length and intensity of work. ${ }^{1}$ Two centuries of unionization and regulation defined work hours for many United States employees, including graduate medical trainees, but left attending physicians largely untouched. Instead, the medical workforce has long relied on survey data to shape jobs that balance professional norms with local market demands. Leaders in young, dynamic specialties, such as pediatric hospital medicine (PHM), particularly require such data to recruit and retain talent.

PHM progressed swiftly from acknowledgment as a "distinct area of practice" in 1999 to a subspecialty recognition. ${ }^{2}$ Currently, at least 3,000 pediatric hospitalists ${ }^{3}$ practice in more than 800 US sites (Snow C, Personal communication regarding community PHM workforce survey). Approximately half of them work at community hospitals, where PHM groups often comprise fewer than five full-time equivalents (FTEs) and face unique challenges. Community PHM practices may assume broader responsibilities than university/children's hospital colleagues, including advocacy for the needs of children in predominantly adult-oriented hospitals. ${ }^{4}$ Although data regarding academic PHM work demands are available, ${ }^{5}$ there is little information pertaining to community hospitalists regarding typical workloads or other characteristics of thriving practices.

In this issue of the Journal of Hospital Medicine, Alvarez et al. present the findings of structured interviews with 70 community PHM group leaders. ${ }^{6}$ Each participant answered 12 questions about their group, addressing the definition of a full-time workload and hours, the design of backup systems, and the respondent's perception of the program's sustainability. The sample is robust, with the caveats that it disproportionately represents the Midwest and West (34.3\% each) and more than half of the groups were employed by an academic institution. The authors found a median work expectation per FTE of 1,882 hours/year and 21 weekends per year, although they noted significant variability in employers' demands and services provided. The majority of hospitalist groups lacked

*Corresponding Author: Rachel L. Marek, MD; E-mail: rlmarek@texaschildrens. org; Telephone: 936-267-5476.

Published online first August 21, 2019.

Received: July 9, 2019; Revised: July 18, 2019; Accepted: July 18, 2019

() 2019 Society of Hospital Medicine DOI 10.12788/jhm.3293 census caps, formal backup systems, or processes to expand coverage during busy seasons. Among the site leaders, $63 \%$ perceived their program as sustainable, but no program design or employer characteristic was clearly associated with this perception.

The importance of this study derives from aggregating data about the largest cross section of community PHM groups yet reported. For many PHM group leaders, this will offer a new point of reference for key practice characteristics. Furthermore, the authors should be commended for attempting to distinguish how program sustainability manifests in community PHM, where hospitalists shoulder longer patient care hours and many of them sustain academic endeavors. It is concerning that more than a third of leaders do not perceive their program as sustainable, but the implications for the field are unclear. Perhaps part of this uncertainty arises from the terminology, as sustainability lacks a technical or a consensus definition and the authors purposefully did not define the term for the respondents. While many respondents probably worried about physician burnout, others might have channeled fears about group finances or competition with adult service lines for beds. In addition, leaders' fears about sustainability may not exactly represent the concerns of front-line employees.

Sustainable work environments are complex constructs with several inputs. For example, supportive leaders, efficient delivery systems, optimized EHRs, competitive pay, and confidence about service line stability might all mitigate higher workloads. Ultimately, this complexity underscores an important caution about all workplace surveys in medicine; ie, average values can inform practice design, but hospitalists and administrators should always consider the local context. Blindly applying medians as benchmarks and ignoring the myriad other contributors to sustainable practice risk disrupting successful PHM programs. In other words, surveys describe how the world is, not how it should be. The spectrum of academic work and norms permeating community PHM groups instead call for a nuanced approach.

How does the field build upon this useful paper? First, the Society of Hospital Medicine (SHM) should engage PHM leaders to increase participation in regular remeasurement, a critical endeavor for this dynamic field. SHM's State of Hospital Medicine Report queries about a wider variety of practice characteristics, but it has a smaller sample size that must grow to fill this void. ${ }^{7}$ As the work of repeated surveys transitions from academic inquiry to professional society service, SHM's Practice Analysis Committee can meet the needs of PHM 
through relevant questions and efforts to foster adequate participation. Second, all practice leaders should follow the ballooning bodies of literature about burnout and healthcare value. Just as labor leaders had discovered in the industrial revolution, sustainable careers require not only measuring work hours but also advocating for safe, meaningful, and engaging work conditions. By continuously creating value for patients,

\section{References}

1. Whaples R. Hours of Work in U.S. History. EH Net Encyclopedia. 2001. http:// eh.net/encyclopedia/hours-of-work-in-u-s-history/. Accessed June 25, 2019.

2. Pediatric Hospital Medicine Certification. The American Board of Pediatrics. https://www.abp.org/content/pediatric-hospital-medicine-certification. Accessed 28 February, 2018.

3. Harbuck SM, Follmer AD, Dill MJ, Erikson C. Estimating the number and characteristics of hospitalist physicians in the United States and their possible workforce implications. Association of Medical Colleges. 2012. www.aamc.org/download/300620/data/aibvol12_no3-hospitalist.pdf. Accessed June 25, 2019.

4. Roberts KB, Brown J, Quinonez RA, Percelay JM. Institutions and individuals: what makes a hospitalist "academic"? Hosp Pediatr. 2014;4(5);326-327. families, and hospitals, we can strengthen our claim to the resources needed to optimize the work environment.

Disclosure: Andrew White is Chair of the Society of Hospital Medicine's Practice Analysis Committee, an unpaid position. Dr. Marek serves on the American Academy of Pediatrics Section on Hospital Medicine Executive Committee which is a voluntary, unpaid, elected position.

https://doi.org/10.1542/hpeds.2014-00.

5. Fromme HB, Chen CO, Fine BR, Gosdin C, Shaughnessy EE. Pediatric hospitalist workload and sustainability in university-based programs: results from a national interview-based survey. J Hosp Med. 2018;13(10):702-705. https://doi. org/10.12788/jhm.2977.

6. Alvarez, F, McDaniel CE, Birnie K, et al. Community pediatric hospitalist workload: results from a national survey. J Hosp Med. 2019; 14(11):682-685. https://doi.org/10.12788/jhm.3263.

7. 2018 State of Hospital Medicine Report. Society of Hospital Medicine: Philadelphia, Pennsylvania; 2019. https://www.hospitalmedicine.org/practice-management/shms-state-of-hospital-medicine/. Accessed July 27, 2019. 